\title{
AVALIAÇÃO FÍSICA, QUÍMICA E FITOQUÍMICA DE FRUTOS DE Physalis, AO LONGO DO PERÍODO DE COLHEITA ${ }^{1}$
}

\author{
CLÁUDIA SIMONE MADRUGA LIMA², SIMONE PADILHA GALARÇA', \\ DÉBORA LEITZKE BETEMPS ${ }^{4}$, ANDREA DE ROSSI RUFATO ${ }^{5}$, LEO RUFATO ${ }^{6}$
}

RESUMO-Physalis peruviana L. é uma espécie que vem sendo incorporada em plantios de pequenas frutas. Esta frutífera é tratada como anual, e o principal método de propagação é por sementes. Seu cultivo apresenta uma dinâmica de colheita diferenciada, com duração do período de colheita superior a três meses. Acredita-se que, devido ao extenso período de colheita, associado a diferentes épocas de semeadura, irão ocorrer variações nas características dos frutos. O objetivo deste trabalho foi avaliar as características físicas, químicas e fitoquímicas de frutos de Physalis peruviana ao longo do período de colheita, em função de duas épocas de plantio. O experimento foi realizado no período de 2007/2008. A semeadura foi realizada em duas épocas (04-09-2007 e 26-11-2007), e o transplante foi realizado quando as plantas estavam no estádio de duas folhas verdadeiras. Os frutos foram colhidos aos 120; 150; 180; 210 e 240 dias após o transplante e avaliados quanto à massa total e a coloração da epiderme, assim como quanto aos seus teores de sólidos solúveis (SS), acidez titulável (AT), fenóis e de carotenoides totais, razão SS/AT e atividade antioxidante. Os frutos de Physalis apresentaram variações físicas, químicas e fitoquímicas ao longo do período de colheita, para as duas datas de semeadura. O desenvolvimento das plantas, após o transplantio, levou a acréscimo nos valores de massa, nos teores de sólidos solúveis, fenóis e carotenoides, assim como na razão SS/AT. Na coloração e na atividade antioxidante, os maiores valores foram obtidos na primeira colheita (120 dias). A semeadura realizada em setembro proporcionou a obtenção de frutos com melhor qualidade.

Termos para indexação: Physalis peruviana, semeadura, transplantio.

\section{PHYSICAL, CHEMICAL AND PHYTOCHEMICAL ASSESSMENT OF Physalis FRUITS OVER THE HARVEST PERIOD}

\begin{abstract}
Physalis peruviana L. is a species that has been introduced in small fruit plantations. It is treated as an annual crop, and its main method of propagation is by seed. Its cultivation presents differentiated harvest dynamics, with a harvesting period duration exceeding three months. It is believed that due to the long harvest associated with different sowing seasons, there may be variations in the fruit characteristics. The aim of this study was to assess the physical, chemical and phytochemical characteristics of Physalis peruviana fruits during the harvest period, according to two sowing seasons. The experiment was carried out in 2007/2008. The seeding was performed at two different times (09/04/2007 and 11/26/2007) and transplantation was performed when fruits were at the second true leaf stage. The fruits were harvested at $120,150,180,210$ and 240 days after transplantation and assessed for total mass and skin color, as well as their soluble solids (SS) content, titratable acidity (TA), phenols and total carotenoids, and also the SS/TA ratio and antioxidant activity. The Physalis fruits present physical, chemical and phytochemical variations through the harvest period for the two sowing seasons. The plant development, after transplantation, led to an increase in mass, soluble solids, phenols and carotenoids as well as the SS/TA ratio. In color and antioxidant activity, the highest values were obtained with the first harvest (120 days). The September sowing provided better quality of fruits.
\end{abstract}

Index terms: Physalis peruviana, sowing, transplanting.

\footnotetext{
'(Trabalho 176-11). Recebido em: 06-06-2011. Aceito para publicação em: 05-09-2012.

${ }^{2}$ Eng. Agrônoma, MSc, Doutoranda em Fruticultura de Clima Temperado pela Universidade Federal de Pelotas,FAEM, Programa de Pós-graduação em Agronomia, Pelotas-RS, Brasil. Email:claudialim@pop.com.br

${ }^{3}$ Eng. Agrônoma, MSc, Doutoranda em Fruticultura de Clima Temperado pela Universidade Federal de Pelotas,FAEM, Programa de Pós-graduação em Agronomia, Pelotas-RS, Brasil. Email:sgalarca@superig.com

${ }^{4}$ Eng. Agrônoma, Msc, Doutoranda em Fruticultura de Clima Temperado pela Universidade Federal de Pelotas,FAEM, Programa de Pós-graduação em Agronomia, Pelotas, RS, Brasil Email: deborabetemps@yahoo.com.br.

${ }^{5}$ Eng. Agrônoma, Dra. Pesquisadora da Embrapa Uva e Vinho, Estação Experimental de Fruticultura Temperada, Vacaria-RS, Brasil. Email: andrea@cnpuv.embrapa.br

${ }^{6}$ Eng. Agrônomo, Dr., Prof. da Universidade do Estado de Santa Catarina,CAV,Lages-SC,Brasil. Email: leoruffato@yahoo.com.br
} 


\section{INTRODUÇÃO}

O grande desenvolvimento de cultivos frutíferos não tradicionais, em relação à produção e à superfície plantada com outras fruteiras, demonstra que o Brasil está descobrindo novos e interessantes mercados, nos quais está interessando (LIMA et al., 2009 a). Uma série de espécies, como a amoreira-preta, a framboeseira, o mirtileiro, o morangueiro e a Physalis tem despertado a atenção de consumidores, processadores, agentes comercializadores e, por consequência dos produtores, seja em escala familiar, seja de médio e grande portes (LIMA et al., 2010).

Uma espécie que está sendo incorporada nos plantios de pequenas frutas, a Physalis peruviana L. é considerada uma excelente alternativa de produção, pelo elevado valor nutracêutico do fruto e pela possibilidade de sua incorporação em cultivos orgânicos (VELASQUEZ et al., 2007). A Physalis tem sido consumida como fruto exótico e com preço bastante elevado, que em 2009 variou de 10 a 25 reais o quilograma (LIMA et al., 2009 b).

O gênero Physalis pertence à família Solanacea e caracteriza-se por apresentar cultivo bastante simples. A maior parte do manejo, tutoramento, adubação, aplicação de herbicidas e irrigação ainda é feito com base na cultura do tomateiro, no Sul do Brasil (RUFATO et al., 2008). A planta é considerada arbustiva e rústica, podendo atingir até dois metros de altura. O fruto é uma baga carnosa, em forma globosa, e desenvolve-se dentro de um cálice formado por cinco sépalas (CHAVES et al., 2005). $\mathrm{O}$ cálice protege o fruto contra insetos, pássaros, patógenos e condições climáticas adversas, e serve de fonte de carboidratos durante os primeiros 20 dias de crescimento. Quando maduro, apresenta coloração alaranjada, com diâmetro que oscila entre $1,25 \mathrm{~cm}$ e $2,50 \mathrm{~cm}$, e massa fresca entre $4 \mathrm{~g}$ e $10 \mathrm{~g}$. Cada planta produz 2 - $3 \mathrm{~kg}$ de fruto por safra (FISCHER; MARTÍNEZ, 1999).

Em frutíferas, como a Physalis, que são tidas como anuais e cujo principal método de propagação é por sementes, a época de semeadura é muito importante em seu manejo agrícola. Além disso, seu cultivo apresenta uma dinâmica de colheita diferenciada quando comparada à maioria das espécies frutíferas, principalmente em relação à duração do período, que para esta espécie é maior que três meses (LIMA et al., 2009 b).

Conforme Casa e Evagelista (2009), as variáveis pós-colheita dependem de uma série de fatores, merecendo destaque a época de semeadura, que deve permitir a realização do cultivo no período mais favorável, em termos de oferta hídrica, calor e luminosidade, assegurando frutos com alta qualidade e menor risco aos produtores.

Acredita-se que, devido ao extenso período de colheita, ocorrem variações nas características dos frutos, em função das distintas épocas de semeadura. Além disso, há o desconhecimento do comportamento físico, químico e fitoquímico da Physalis ao longo do período de colheita. Estudos que relacionem a época de semeadura e a qualidade dos frutos dessa espécie fazem-se necessários, pois podem fornecer informações importantes sobre a melhor época de plantio e de colheita dos frutos, bem como as possibilidades de exploração destes frutos, de acordo com suas características, ao longo do período de colheita.

O objetivo deste trabalho foi avaliar as características físicas, químicas e fitoquímicas de frutos de Physalis ao longo do período de colheita, em duas épocas de plantio.

\section{MATERIAL E MÉTODOS}

O experimento foi desenvolvido em um pomar experimental localizado no município do Capão do Leão-RS (latitude de 31 ${ }^{\circ} 52^{\prime} 00$ " S, longitude de $52^{\circ} 21^{\prime} 24$ " W e altitude 13,24 metros), durante o ano agrícola de 2007/2008. O clima da região caracteriza-se como temperado úmido, com verões quentes, tipo Cfa, conforme a classificação de Köppen. A região possui temperatura e precipitação médias anuais de $17,9^{\circ} \mathrm{C}$ e $1.500 \mathrm{~mm}$ (EAPel, 2009).

Foram utilizadas mudas de Physalis produzidas em bandejas de poliestireno expandido, com 128 células, preenchidas com o substrato comercial $\left(\right.$ Plantmax $\left.^{\circledR}\right)$, em condições de telado. A semeadura foi realizada em duas épocas, (04-09-2007 e 26-112007) e o transplante efetuado quando as plantas apresentavam duas folhas verdadeiras e aproximadamente $20 \mathrm{~cm}$ de comprimento, em duas épocas (20-11-2007 e 14-01-2008), em solo com pH corrigido para 6,0. A adubação foi feita de acordo com o recomendado para a cultura do tomateiro e visando a uma produção de $20 \mathrm{t} \mathrm{ha}^{-1}$ (RUFATO et al., 2008). As plantas foram tutoradas, utilizando-se de estacas de bambu com espaçamento de 1 metro entre plantas e 3,5 metros entre linhas. O sistema de irrigação adotado foi o gotejamento. Não foram realizadas atividades de poda, desponte, desbrote e/ou raleio.

Os frutos foram colhidos quando a coloração do cálice se tornou amarelo-esverdeada, sendo utilizadas 25 frutas por repetição, totalizando 75 frutas/data de colheita, de cada época de semeadura. Avaliou-se a massa dos frutos, que foi realizada em balança digital, pesando-se os frutos com talo e 
cálice, e depois da eliminação destes. A coloração da epiderme foi determinada com duas leituras, em lados opostos, na região equatorial do fruto, empregando-se colorímetro Minolta CR-300, e foram expressas em ângulo Hue. Os teores de sólidos solúveis (SS) foram determinados, utilizando-se de refratômetro de mesa Shimadzu, com correção de temperatura para $20^{\circ} \mathrm{C}$, que se expressa em graus Brix; os de acidez titulável (AT), expressos em \% de ácido cítrico, foram determinados por titulação de $10 \mathrm{~mL}$ de suco diluído em $90 \mathrm{~mL}$ de água destilada, com $\mathrm{NaOH}$ a $0,1 \mathrm{M}$, até pH 8,1, medido em equipamento Digimed DMPH - 2, com correção automática de temperatura, e a relação entre os teores de sólidos solúveis e acidez titulável (SS/AT).

O teor de carotenoides totais foi quantificado de acordo com o método espectrofotométrico proposto por Rodriguez-Amaya (2001). A extração dos carotenoides foi feita usando-se cinco gramas de polpa fresca, previamente congelada em nitrogênio líquido, com $20 \mathrm{~mL}$ de acetona a $-20{ }^{\circ} \mathrm{C}$ e posterior filtração a vácuo. A esta mistura foram acrescentados $30 \mathrm{~mL}$ de éter de petróleo, e a amostra foi lavada com água destilada até a remoção completa da acetona. A amostra foi transferida para balão volumétrico de $50 \mathrm{~mL}$, e o volume foi completado com éter de petróleo. As leituras foram realizadas em espectrofotômetro a 450 $\mathrm{nm}$, e os resultados, expressos em $\mu \mathrm{g} \beta$ caroteno $\mathrm{g}^{-1}$.

O teor de compostos fenólicos totais foi determinado pelo método modificado de Folin-Ciocalteu (SINGLETON; ROSSI, 1965), a partir de um grama de massa fresca de polpa congelada com nitrogênio líquido, que foi homogeneizada com $60 \mathrm{~mL}$ de água ultrapura e adicionada de $5 \mathrm{~mL}$ do Reagente de Folin-Ciocalteu. Após 8 minutos foi feita a neutralização com $20 \mathrm{~mL}$ de solução saturada de carbonato de sódio. A absorbância da solução resultante foi medida a $725 \mathrm{~nm}$, após duas horas de reação em ambiente protegido da luz. Os resultados foram expressos em mg GAE $100 \mathrm{~g}^{-1}$ (equivalente ácido gálico por 100 $\mathrm{g}$ de massa fresca de fruta), a partir de curva-padrão com ácido gálico.

A capacidade antioxidante foi determinada de acordo com Re et al. (1999), a partir da utilização do radical ABTS (2,2'azino-bis-3-etilbenzotiazolin 6-ácido sulfônico), em que cinco gramas de polpa congelada em nitrogênio líquido foram homogeneizados com $50 \mathrm{~mL}$ de água ultrapura, a $4^{\circ} \mathrm{C}$. A uma alíquota de $5 \mathrm{~mL}$ deste homogeneizado, foram adicionados $5 \mathrm{~mL}$ de álcool etílico a $95 \%$ (v/v), seguido de centrifugação a $10.000 \mathrm{x} \mathrm{g}$, a $4^{\circ} \mathrm{C}$, durante 10 minutos. Do sobrenadante, foram tomados $10 \mu \mathrm{L}$ que foram adicionados a $990 \mu \mathrm{L}$ de solução etanólica de ABTS a $7 \mathrm{mM}$. Após 30 minutos de reação no escuro e a $4^{\circ} \mathrm{C}$, as leituras foram realizadas em espectrofotômetro a $734 \mathrm{~nm}$, e os resultados, expressos em $\mu \mathrm{mol}$ equivalente Trolox por grama de massa fresca do fruto (TE $\mathrm{MF} \mathrm{g}^{-1}$ ), em relação a uma curva-padrão com Trolox (6-Hidroxi-2,5,7,8-tetrametilchroman-2-ácido carboxílico).

O delineamento experimental utilizado foi o inteiramente casualizado, com três repetições. Os tratamentos formaram um fatorial $5 \times 2$, com os fatores dias após transplante (dat) em cinco níveis $(120 ; 150 ; 180 ; 210$ e 240$)$, e o fator épocas de semeadura, em dois níveis:04-09-2007 e 26-11-2007. Os dados foram submetidos à análise de variância, e as médias, comparadas através do teste de Tukey, a $5 \%$ de probabilidade de erro.

\section{RESULTADOS E DISCUSSÃO}

Na primeira época de semeadura (04-092007), a massa das frutas, sem talo e sem cálice, apresentou acréscimo até os 240 dias após o transplantio (dat), realizado em julho, chegando ao máximo de $6,04 \mathrm{~g}$, sem diferir da colheita realizada aos 210 dat (junho). Na $2^{a}$ época de semeadura (26-11-2007), os frutos mantiveram o comportamento de acréscimo de massa verificado na época, sendo a massa máxima de 4,76 g, obtida aos 240 dat. As frutas colhidas aos 180; 210 e 240 dias após o transplante, na $2^{\mathrm{a}}$ época, apresentaram valores de massa de 4,29g a 4,76 g, que se mostraram estatisticamente diferentes (Figura 1A). Aguilar et al. (2006), em Chapingo, no México, obtiveram frutos com massa entre 2,00g e 7,40 g, em plantas de Physalis fertirrigadas. No entanto, Fischer e Almanza (2002), em Bogotá, na Colômbia, obtiveram frutas com massa de 4,00g a 8,50 g.

Essa tendência também foi observada para a massa total das frutas pesadas com talos e cálices. Para a primeira época de semeadura, a massa total das frutas variou entre $4,0 \mathrm{~g}$ e $7,0 \mathrm{~g}$ e entre $3,0 \mathrm{~g}$ e 5,0 g. na $2^{\mathrm{a}}$ época. Os maiores resultados foram obtidos aos 240 dat, que se refere ao mês de julho na $1^{\text {a }}$ época $(7,00 \mathrm{~g})$ e de setembro na $2^{\mathrm{a}}$ época $(5,61 \mathrm{~g})$. Observa-se que, a partir dos 150 dat, a massa dos frutos é superior a $5 \mathrm{~g}$ na $1^{\mathrm{a}}$ época e a $4 \mathrm{~g}$ na $2^{\mathrm{a}}$ época (Figura 1B). De acordo com Fischer e Martínez (1999), a massa total das frutas bem desenvolvidos de Physalis está entre $4 \mathrm{~g}$ e $10 \mathrm{~g}$ e mencionam que esta fruta é comercializada com talo e cálice. Desse modo, para se obter resposta de massa total equivalente ao praticado no comércio, devem-se mensurar os três componentes (LIMA et al., 2009b). Apenas os frutos colhidos na segunda época de semeadura, ou aos 120 dat (maio) não poderiam ser comercializados in 
natura, por apresentarem valores abaixo do indicado pelas normas de exportação da Colômbia (CODEX, 2005), que devem ter massa mínima de $4 \mathrm{~g}$.

Os valores encontrados para a massa fresca das frutas, com e sem cálice, ao longo do período de colheita, podem estar relacionados com a dinâmica de frutificação de Physalis. De acordo com Rufato et al. (2008), esta frutífera apresenta extenso período de colheita e possui pico de frutificação por volta dos 180 dat, quando ocorre diminuição no número de frutos, modificando a relação fonte: dreno.

De acordo com as Figuras 1A e 1B, observa-se que os frutos oriundos da primeira época de semeadura foram maiores, o que reafirma o indicado por Salazar et al. (2008), ou seja, que o cultivo de Physalis, em épocas com temperaturas de aproximadamente $25^{\circ} \mathrm{C}$, tende a favorecer o crescimento vegetativo, principalmente o número de folhas, favorecendo o melhor desenvolvimento e crescimento dos frutos. Em períodos de clima ameno, aproximadamente $14^{\circ} \mathrm{C}$, ocorre estímulo à floração e frutificação precoces, ou seja, o ciclo tende a ser mais curto, com plantas cujo número de folhas e frutos, assim como altura e diâmetro são menores.

A coloração dos frutos, indicada pelos valores do ângulo Hue, variou entre 75,17 e 78,39, nos produzidos na primeira época de plantio, e entre 73,12 e 78,23 na segunda época. Os maiores valores foram obtidos aos 150 dat, ou nos períodos de abril a junho, $1^{\text {a }}$ e $2^{\text {a }}$ épocas, respectivamente, que diferiram dos demais meses. Os menores valores foram verificados aos 240 dat, nas duas épocas de semeadura (Figura 2).

Os frutos colhidos em ambas as épocas apresentaram coloração adequada à comercialização, conforme o Instituto Colombiano de Normas Técnicas (ICONTEC, 1999), ou seja, os frutos de Physalis possuíam coloração do alaranjado ao alaranjado intenso. As respostas obtidas para a coloração indicam que, na primeira época de semeadura, os frutos apresentavam coloração mais alaranjada do que os da segunda época.

Conforme Fischer et al. (2005), os dias mais longos e temperaturas mais altas favorecem o crescimento vegetativo e produtivo das plantas de Physalis. Os frutos oriundos da primeira época de semeadura foram submetidos a um período com maiores temperaturas e dias mais longos, com produção de frutos com coloração alaranjada mais forte. Acredita-se que a redução na temperatura e no comprimento do dia, ao longo do período de colheita, tenha favorecido a redução do ângulo Hue durante as colheitas.

$\mathrm{Na} 1^{\mathrm{a}}$ época de semeadura, o conteúdo de sólidos solúveis foi maior que na segunda, e nas duas estes teores aumentaram com o tempo para a colheita. $\mathrm{Na}$ primeira época, as médias encontradas em julho (240 dat) diferiram significativamente dos resultados observados em março (120 dat), abril (150 dat), maio (180 dat) e junho (210 dat) (Tabela 1). Segundo Vega et al. (1991), as Physalis produzem, nas primeiras colheitas, frutos com menores teores de sólidos solúveis, aproximadamente $9,0^{\circ} \mathrm{Brix}$. Os valores encontrados neste trabalho são semelhantes aos obtidos por Lizana e Espina (1991), em Santiago, no Chile, cujos teores, no momento da colheita, ficaram entre $12^{\circ}$ Brix e $15^{\circ}$ Brix. No entanto, Aguilar et al. (2006), em Chapingo, no México, encontraram teores entre $8,5^{\circ}$ Brix e $12^{\circ}$ Brix em frutos de plantas com um ano, e de 7,2 a $11,2^{\circ}$ Brix para plantas com dois anos. Em todas as datas de colheita, o teor de sólidos solúveis foi maior quando a semeadura foi realizada mais cedo, no caso, em 04-09-2007 (primeira época).

Os resultados para os teores de acidez titulável foram inversos aos obtidos para os de sólidos solúveis. A maior percentagem foi obtida na $2^{\mathrm{a}}$ época, aos 120 dat $(0,78 \%$ ác. cítrico), que diferiram das demais médias. O menor percentual de ácido cítrico foi obtido nas colheitas realizadas a partir dos 180 dat, com valores de $0,64 \%$ a $0,62 \%$ ác. cítrico (Tabela 1 ). Os maiores percentuais de ácido cítrico são identificados nas primeiras colheitas, e por este motivo muitos autores recomendam eliminar a primeira floração (GARCIAZ, 1982; AGOS et al., 2007). Lizana e Espina (1991), em Santiago, no Chile, relataram que o percentual de ácido cítrico foi bastante instável entre as colheitas, com valores entre 0,70 e $0,80 \%$ ác. cítrico. As menores médias para a relação SS/AT foram observadas aos 120 dat, para as duas épocas de semeadura, indicando que os frutos estavam mais ácidos do que o desejável, sendo que as colheitas realizadas no mês de julho, aos 240 dat, resultaram nas maiores relações SS/AT. Os maiores valores obtidos na $1^{a}$ época (19 a 24) indicam que o sabor destes frutos era mais doce que os da $2^{\mathrm{a}}$ época (17 a 22) (Tabela 1).

Os resultados verificados para as variáveis sólidos solúveis, acidez titulável e relação SS/AT podem estar relacionados com a ocorrência de senescência, pois nos meses finais de colheita (210 e 240 dat), as plantas começam a apresentar redução nas taxas de crescimento, principalmente no número de folhas e frutos (MÁRQUEZ et al., 2009). Conforme Severo et al. (2009), na senescência, a atividade respiratória é intensa, com a utilização do ácido cítrico como substrato do ciclo respiratório, enquanto os sólidos solúveis aumentam, devido ao aumento nos processos degradativos das paredes celulares e da lamela média.

Para a variável carotenoides totais, os teores 
aumentaram com o passar dos dias após o transplante, estabilizando-se após 150-210 dat, com os maiores teores ocorrendo dos 150 aos 240 dat (Figura 3). Estes valores são superiores aos encontrados por Carrasco e Zelada (2008) em frutas frescas $(79,5 \mu \mathrm{g} \beta$ caroteno $\left.\mathrm{g}^{-1}\right)$. Conforme Severo et al. (2010), os carotenoides majoritariamente presentes em frutas de Physalis são $\beta$-criptoxantina, seguida pelo $\beta$-caroteno e licopeno.

Os conteúdos de carotenoides encontrados neste experimento são superiores aos obtidos por Marinova e Ribarova (2007) em amora-preta $(4,4$ $\mu \mathrm{g} \beta$ caroteno $\left.\mathrm{g}^{-1}\right)$ e mirtilo $\left(2,9 \mu \mathrm{g} \beta\right.$ caroteno $\left.\mathrm{g}^{-1}\right)$, assim como os verificados por Lima et al. (2005) em acerola, 26,6 $\mu \mathrm{g} \beta$ caroteno $\mathrm{g}^{-1} \mathrm{e}$ os obtidos por Jacques et al. (2009) em frutos de butiá e pitanga-roxa $(28,0$ e $45,3 \mu \mathrm{g}$ Bcaroteno $\mathrm{g}^{-1}$ ).

Os frutos produzidos na $1^{\mathrm{a}}$ época apresentaram maior teor de fenóis totais que os produzidos na $2^{\text {a }}$ época de semeadura, em todo o período de produção (Tabela 2). O teor de fenóis totais nos frutos produzidos na $1^{\mathrm{a}}$ época aumentou com o tempo após o transplante, estabilizando-se aos 210 dat, enquanto nos da $2^{\text {a }}$ época este conteúdo aumentou até os 240 dat. Estes valores podem ser considerados baixos se comparados com outras frutas, como a pitanga- roxa (420,8 mg EAG $100 \mathrm{~g}^{-1}$ ), o butiá (328,6 mg EAG 100 $\left.\mathrm{g}^{-1}\right)$, a amora cv. Xavante (731,4 mg EAG $\left.100 \mathrm{~g}^{-1}\right)$ e o mirtilo cv. Delite (750,5 mg EAG $100 \mathrm{~g}^{-1}$ ), conforme o relatado por Jacques et al. (2009).

O potencial antioxidante das frutas de Physalis foi diminuindo com o tempo de colheita,

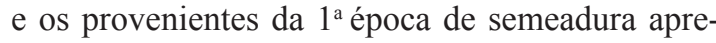
sentaram maior capacidade antioxidante que os da segunda (Tabela 2). Estes valores são inferiores aos quantificados por Rockenbach et al. (2008), que foram de $31 \mu \mathrm{mol} \mathrm{g}{ }^{-1}$. Segundo Frankel (1993), os valores da capacidade antioxidantes dos vegetais é amplamente influenciado por fatores genéticos, condições ambientais, além do grau de maturação, variedade da planta pelo solvente e a técnica de extração empregados.

TABELA 1 - Teores de sólidos solúveis (SS), acidez titulável (AT) e da relação SS/AT em frutos de Physalis, no momento da colheita em função dos dias após o transplante e das épocas da semeadura. Pelotas-RS

\begin{tabular}{|c|c|c|c|}
\hline \multirow{3}{*}{ Variáveis } & \multirow{3}{*}{ Colheita (dat) } & \multicolumn{2}{|c|}{ Épocas de semeadura } \\
\hline & & 1 & 2 \\
\hline & & $(04-09-2007)$ & $(26-11-2007)$ \\
\hline \multirow{6}{*}{ SS $\left({ }^{\circ}\right.$ Brix $)$} & 120 & $14,28 \mathrm{cA}$ & $13,47 \mathrm{bB}$ \\
\hline & 150 & $14,44 \mathrm{bcA}$ & $14,36 \mathrm{bB}$ \\
\hline & 180 & $14,59 \mathrm{bA}$ & $14,37 \mathrm{bB}$ \\
\hline & 210 & $15,00 \mathrm{bA}$ & $14,80 \mathrm{aB}$ \\
\hline & 240 & $15,25 \mathrm{aA}$ & $14,82 \mathrm{aB}$ \\
\hline & Média Geral & \multicolumn{2}{|c|}{14,50} \\
\hline \multirow{7}{*}{ AT (\% ác. cítrico) } & CV (\%) & \multicolumn{2}{|c|}{5,00} \\
\hline & 120 & $0,73 \mathrm{aB}$ & $0,78 \mathrm{aA}$ \\
\hline & 150 & $0,72 \mathrm{aB}$ & $0,73 \mathrm{bA}$ \\
\hline & 180 & $0,64 \mathrm{bB}$ & $0,69 \mathrm{bcA}$ \\
\hline & 210 & $0,63 \mathrm{bB}$ & $0,67 \mathrm{cA}$ \\
\hline & 240 & $0,62 \mathrm{bB}$ & $0,67 \mathrm{cA}$ \\
\hline & Média Geral & \multicolumn{2}{|c|}{0,68} \\
\hline \multirow{8}{*}{ Relação SS/AT } & CV (\%) & \multicolumn{2}{|c|}{2,34} \\
\hline & 120 & $19,57 \mathrm{eA}$ & $17,26 \mathrm{~dB}$ \\
\hline & 150 & $20,05 \mathrm{dA}$ & $19,67 \mathrm{cA}$ \\
\hline & 180 & $20,84 \mathrm{cA}$ & $20,80 \mathrm{bB}$ \\
\hline & 210 & $23,80 \mathrm{bA}$ & $22,08 \mathrm{aB}$ \\
\hline & 240 & $24,59 \mathrm{aA}$ & $22,11 \mathrm{aB}$ \\
\hline & Média Geral & \multirow{2}{*}{\multicolumn{2}{|c|}{$\begin{array}{c}21,00 \\
3,11\end{array}$}} \\
\hline & CV $(\%)$ & & \\
\hline
\end{tabular}

*Médias seguidas de pelo menos uma letra comum, minúscula na coluna ou maiúscula na linha, não diferem entre si, pelo teste de Tukey $(\mathrm{p} \leq 0,05)$. 
TABELA 2 - Teores de fenóis totais e capacidade antioxidante de frutos de Physalis, no momento da colheita em função dos dias após o transplante e das épocas da semeadura, Pelotas-RS.

\begin{tabular}{|c|c|c|c|}
\hline \multirow[b]{2}{*}{ Variáveis } & \multirow[b]{2}{*}{ Colheita (Dias após o transplante) } & \multicolumn{2}{|c|}{ Épocas de semeadura } \\
\hline & & $\begin{array}{c}1^{\mathrm{a}} \\
(04 / 09 / 2007)\end{array}$ & $\begin{array}{c}2^{\mathrm{a}} \\
(26 / 11 / 2007)\end{array}$ \\
\hline \multirow{8}{*}{$\begin{array}{l}\text { Fenóis totais } \\
\left(\mathrm{mg} 100 \mathrm{~g}^{-1}\right)\end{array}$} & 120 & $180,05 \mathrm{dA}$ & $150,04 \mathrm{eB}$ \\
\hline & 150 & $195,01 \mathrm{cA}$ & $164,55 \mathrm{~dB}$ \\
\hline & 180 & $198,07 \mathrm{bA}$ & $184,33 \mathrm{cB}$ \\
\hline & 210 & $200,11 \mathrm{aA}$ & $194,44 \mathrm{bB}$ \\
\hline & 240 & $210,04 \mathrm{aA}$ & $199,33 \mathrm{aB}$ \\
\hline & Média Geral & \multicolumn{2}{|c|}{187,59} \\
\hline & $\mathrm{CV}(\%)$ & \multirow{2}{*}{\multicolumn{2}{|c|}{9,34}} \\
\hline & 120 & & \\
\hline & 150 & $1,66 \mathrm{Ab}$ & $1,54 \mathrm{Bb}$ \\
\hline Capacidade & 180 & $1,44 \mathrm{Ac}$ & $1,40 \mathrm{Bc}$ \\
\hline antioxidante & 210 & $1,39 \mathrm{Ad}$ & $1,28 \mathrm{Bd}$ \\
\hline \multirow[t]{3}{*}{$\left(\mu \mathrm{molTE} \mathrm{g}^{-1}\right)$} & 240 & $1,28 \mathrm{Ae}$ & $1,14 \mathrm{Be}$ \\
\hline & Média Geral & \multirow{2}{*}{\multicolumn{2}{|c|}{$\begin{array}{c}1,45 \\
10,32\end{array}$}} \\
\hline & $\mathrm{CV}(\%)$ & & \\
\hline
\end{tabular}

*Médias seguidas por letra distinta minúscula na coluna ou maiúscula na linha diferem entre si, pelo teste de Tukey $(\mathrm{p} \leq 0,05)$.
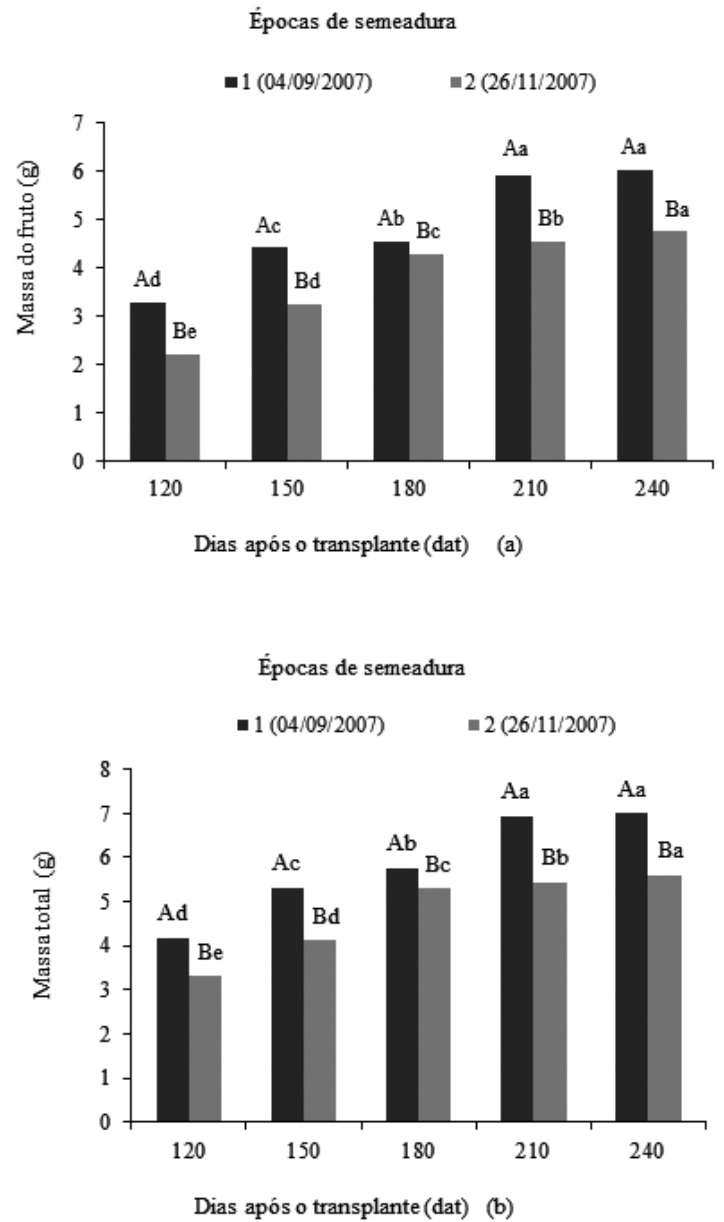

FIGURA 1 - 'Massa dos frutos de Physalis sem talo e cálice (A) e com talo e cálice (B), no momento da colheita em função dos dias após o transplante e das épocas da semeadura. Pelotas-RS.

Colunas indicadas com letras distintas diferem enre si, pelo teste de Tukey ( $\mathrm{p}>0.05)$. Letras minúsculas comparam dias após o transplante dentro de cada época e letras maiúsculas. épocas de semeadura em cada data. 
Épocas de semeadura

- $1(04 / 09 / 2007) \quad \square 2(26 / 11 / 2007)$

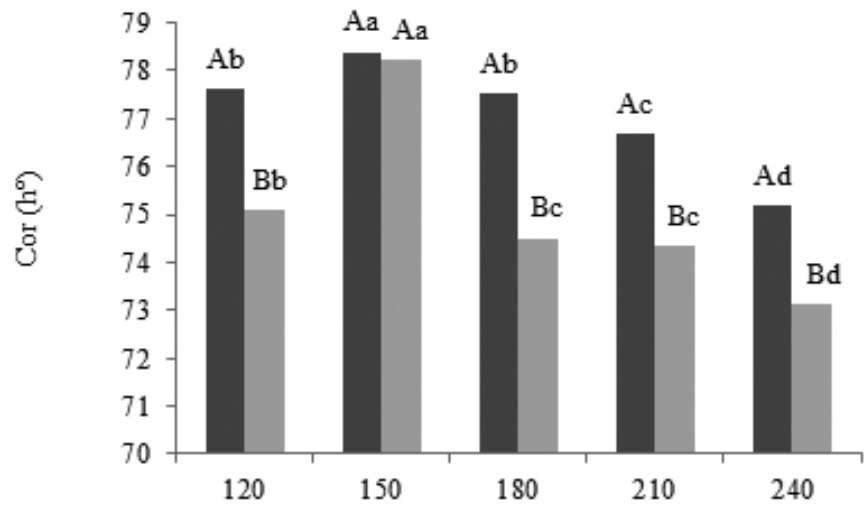

Dias após o transplante (dat)

FIGURA 2- Ângulo Hue da coloração da epiderme de frutas de Physalis, no momento da colheita, em função dos dias após o transplante e das épocas de semeadura. Pelotas-RS.

*Colunas indicadas com letras distintas diferem entre si, pelo teste de Tukey ( $\mathrm{p}>0,05)$. Letras minúsculas comparam dias após o transplante e letras maiúsculas, épocas de semeadura.

\section{Épocas de semeadura}

$\square 1(04 / 09 / 2007) \quad-2(26 / 11 / 2007)$

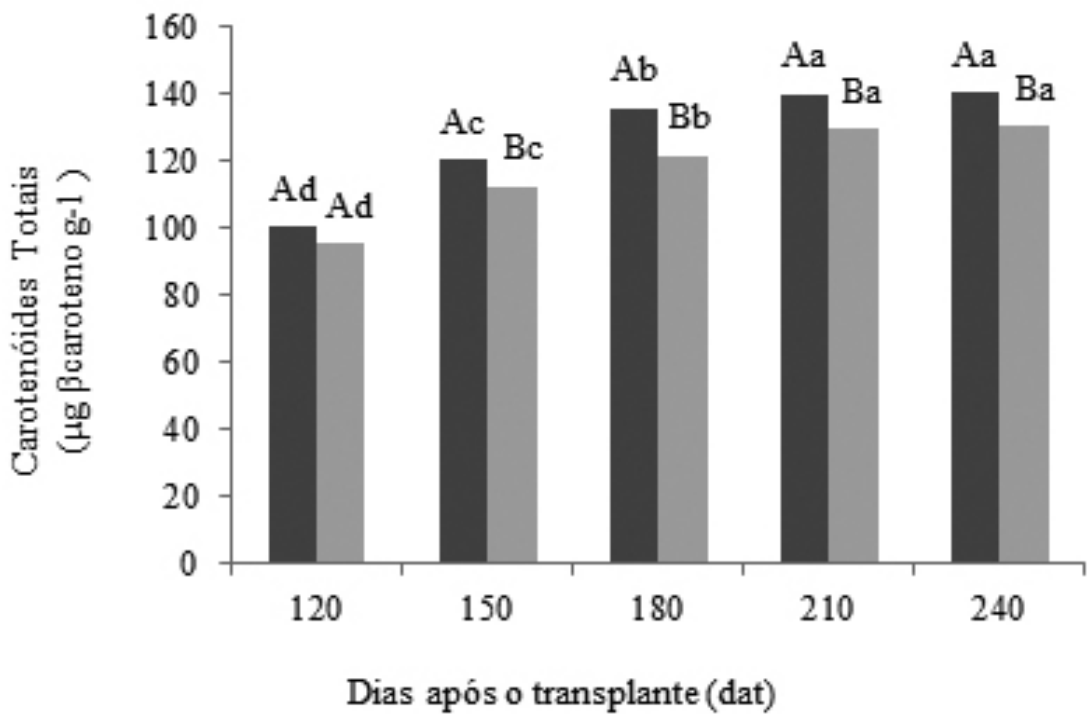

FIGURA 3 - Teores de carotenoides totais em frutos de Physalis, no momento da colheita em função dos dias após o transplante e das épocas da semeadura, Pelotas-RS.

*Colunas indicadas com letras distintas diferem entre si, pelo teste de Tukey ( $p>0,05)$. Letras minúsculas comparam dias após o transplante e letras maiúsculas, épocas de semeadura. 


\section{CONCLUSÕES}

1-Os frutos de Physalis apresentaram variações físicas, químicas e fitoquímicas ao longo do período de colheita para as duas datas de semeadura.

2-A semeadura de Physalis realizada no início do mês de setembro produziu frutas com maior massa, coloração típica, teores de sólidos solúveis, carotenoides totais e fenóis totais, assim como alta relação sólidos solúveis/acidez titulável e capacidade antioxidante.

3-Os frutos colhidos aos 210 e 240 dat apresentam as melhores características físicas,químicas e maior concentração de carotenoides totais e fenóis totais.

\section{REFERÊNCIAS}

AGOS, T.; VALLEJO, F.; CRIOLLO, H. Análisis de la aptitud combinatoria de algunas características del fruto de Physalis peruviana L. Agronomía Colombiana, Bogotá, v.25, p.36-46. 2007.

AGUILAR, M. R.; LOMELI, A.P.;GAYTAN,E.L.;H ERNADEZ,J.J.A.;AGUIRRE,D.P. Agrofenología de Physalis peruviana L. en invernadero y fertirriego. Revista Chapingo, Chapingo, v.12, p.57-63, 2006.

CARRASCO, R.R. DE; ZELADA, C.R.E. Determinacion de la capacidade antioxidante $y$ compuestos bioactivos de frutas nativas peruanas. Revista de la Sociedad Quimica del Peru, Lima, v.74, p.108-124, 2008.

CASA, J.; EVAGELISTA, R. M. Influência das épocas de colheita na qualidade de tomate cultivado em sistemas alternativos. Semina: Ciências Agrárias, Londrina, v. 30, p. 1.101-1.108, 2009.

CHAVES, A.C.; SCHUCH, M.W.; ERIG, A.C. Estabelecimento e multiplicação in vitro de Physalis peruviana L. Revista Ciência e Agrotecnologia, Lavras, v. 29, p.1.281-1.287, 2005.

CODEX STAN, Norma del codex para la uchuva. Colômbia: Codex Stan, 2005. 14p.

EAPel- Estação Agroclimatólogica de Pelotas. Disponível em: <http://www.cpact.embrapa.br/ agromet/ estacao/index.html > Acesso em: 20 jan. 2009.
FISCHER, G.; ALMANZA, P.J. Nuevas tecnologías en el cultivo de la uchuva Physalis peruviana. Revista Expedición Científica y Cultural, Bogotá, v.9, p.1-19, 2002.

FISCHER, G.; MARTÍNEZ, O. Calidad y madurez de la uchuva (Physalis peruviana L.) en relación con la coloración del fruto. Agronomía Colombiana, Bogotá, v.16, p. 35-39, 1999.

FISCHER, G; MIRANDA, D; PIEDRAHÍTA, W; ROMERO, J. Avances en cultivo, poscosecha y exportación de la uchuva (Physalis peruviana L.) en Colombia. Bogotá: Universidad Nacional de Colombia. 2005. 221p.

FRANKEL, E.N. In search of better methodos to evaluate natural antioxidant and oxidative stability in food lipids. Trends in Food Sciensce \& Technology, Cambridge, v.4, p.220-225, 1993.

GARCIAZ. A.D. O cultivo de la uchuva. Bogotá:ARME, 1982. 11p.

ICONTEC -Instituto Colombiano De Normas Técnicas Y Certificación. Norma técnica colombiana uchuva. Bogotá, 1999. 5p. (NTC, 4580).

JACQUES, A.C.; PERTUZATTI, P.B.; BARCIA, M.T. ZAMBIAZI, R.C. Compostos Bioativos em pequenas frutas cultivadas na região sul do Estado do Rio Grande do Sul. Brazilian Journal of Food Technology, Campinas, v.12, p. 123-127, 2009.

LIMA, C.S.M.; GONÇALVES, M.A.; TOMAZ, Z.F.P.; RUFATO, A.R.; FACHINELLO, J. C. Sistemas de tutoramento e épocas de transplante de physalis. Ciência Rural, Santa Maria, v.40, p. 2472-2479, 2010.

LIMA, C.S.M.; MANICA-BERTO, R.; BETEMPS, D.L.; SILVA, S.J.P.; RUFATO, A.R. Custos de implantação e condução de pomar de Physalis na região sul do estado do Rio Grande do Sul. Revista Ceres, Viçosa, MG, v.56, p.551-561, 2009 a.

LIMA, C. S. M.; SEVERO, J.; MANICABERTO,R.; SILVA, J.A.; RUFATO,L; RUFATO, A.R. Características físico-químicas de physalis em diferentes colorações do cálice e sistemas de condução. Revista Brasileira de Fruticultura, Jaboticabal, v.31, p.1061-1068, 2009 b. 
LIMA, V. L. A. G.; MÉLO, E. A.; MACIEL, M. I. S.; PRAZERES, F. G.; MUSSER, R. S.; LIMA, D. E. S. Total phenolic and carotenoid contentes in acerola genotypes harvested at three ripening stages. Food Chemistry, London, v. 90, p. 565-568, 2005.

LIZANA, A.; ESPINA, S. Efecto de la temperatura de almacenaje sobre el comportamiento en poscosecha de frutos de fisalis (Physalis peruviana L.). Interamerican Society for Tropical Horticulture, Santiago, v.35, p.278-284, 1991.

MARINOVA, D.; RIBAROVA, F.; HPLC determination of carotenoids in Bulgarian berries. Journal of Food Composition and Analysis, Amsterdam, v. 20, p. 370-374, 2007.

MÁRQuEZ, C. J. C., TRILloS, O. G.; CARTAGENA, J.R. V.; COTES, J. M.T. Evaluación físico-quimica y sensorial de frutos de uchuva (Physalis peruviana 1.). Revista de la Facultad de Química Farmacéutica, Antioquia, v.16, p.42-48, 2009.

RE, R; PELLEGRINI, N.; PROTEGGENTE, A.; PANNALA, A.; YANG, M.; RICE-EVANS, C. Antioxidant activity applying an improved ABTS radical cation decolorizing assay. Free Radical Biology and Medicine, New York, v. 26, p.12311237, 1999.

ROCKENBACK, I.I.; RODRIGUES, E.; CATANEO, C.; GONZAGA, L.V.; LIMA, A.; MANCINIFILHOFETT, J. Ácidos fenólicos e atividade antioxidante em fruto de Physalis peruviana L. Alimentos e Nutrição, Araraquara, v.19, p. 271 276, 2008.

RODRÍGUEZ-AMAYA D. A guide to carotenoids analysis in food. Washington: International Life Sciences Institute Press, 2001. 64p.

RUFATO, L.; RUFATO, A.R.; SCHELEMPER,C.; LIMA,C.S.M.; KRETZSCHMAR, A. A. Aspectos técnicos da cultura da Physalis. Lages: CAV/ UDESC; Pelotas: UFPel, 2008. 100p.
SALAZAR, M. R., JONES, J. W.; CHAVES, B.; COOMAN, A.; FISCHER, G. Base temperature and simulation model for nodes appearance in cape gooseberry (Physalis peruviana L.). Revista Brasileira de Fruticultura, Jaboticabal, v.30, p. 862-867, 2008.

SEVERO, J.; GALARÇA, S.P.; AIRES, R.F.; CANTILLANO,R.F.F.; ROMBALDI,C.V., SILVA, J.A. Avaliação de compostos fenólicos, antocianinas, vitamina $\mathrm{C}$ e capacidade antioxidante em mirtilo armazenado em atmosfera controlada. Brazilian Journal of Food Technology, Campinas, v. 52, p.65-70, 2009

SEVERO, J.; LIMA, C. S. M.; COELHO, M. T.; RUFATO, A. DE R.; ROMBALDI, C. V.; SILVA, J. A. Atividade antioxidante e fitoquímicos em frutos de physalis (Physalis peruviana, L.) durante o amadurecimento e o armazenamento. Revista Brasileira de Agrociência, Pelotas, v. 16, p.112$121,2010$.

SINGLETON, V. L.; ROSSI, J.A. Jr. Colorimetry of total phenolics with phosphomolybdicphosphotungstic acid reagents. American Journal of Enology and Viticulture, Davis, v.16, p.144-158, 1965.

VEGA, A.; ARAOS, R.; ESPINA, S.; LIZANA, A. Crescimento del fruto de Physalis (Physalis peruviana) y determinación del indice de cosecha. Interamerican Society for Tropical Horticulture, Santiago, v.35, p.23-28. 1991.

VELASQUEZ, H.J.C.; GIRALDO, O.H.B.; ARANGO, S.S.P.; Estudio preliminar de la resistencia mecánica a la fractura y fuerza de firmeza para fruta de uchuva (Physalis peruviana L.). Revista Facultad Nacional de Agronomía, Medellín, v. 60, p. 3785 3796, 2007. 